\title{
Manufacturing of a Bimetallic Structure of Stainless Steel and Mild Steel through Wire Arc Additive Manufacturing - A Critical Review
}

\author{
Anirudhan B T \\ Department of Metallurgical and Materials Engineering \\ Amal Jyothi College of Engineering Kanjirappally, \\ Kottayam-686518 Kerala, India \\ Tejaswin Krishna \\ Department of Metallurgical and Materials Engineering \\ Amal Jyothi College of Engineering Kanjirappally, \\ Kottayam-686518 Kerala, India
}

\author{
Jithin Devasia \\ Department of Metallurgical and Materials Engineering \\ Amal Jyothi College of Engineering Kanjirappally, \\ Kottayam-686518 Kerala, India \\ Mebin T Kuruvila* \\ Department of Metallurgical and Materials Engineering \\ Amal Jyothi College of Engineering Kanjirappally, \\ Kottayam-686518 Kerala, India
}

\begin{abstract}
Wire and Arc based Additive Manufacturing, shortly known as WAAM, is one of the most prominent tech- nologies, under Additive Manufacturing, used for extensive production of complex and intricate shapes. This layer by layer deposition method avails arc welding technology; Gas Metal Arc Welding (GMAW), a competitive method in WAAM, is the conducted manufacturing process.
\end{abstract}

It is a sum of heat source, originated from the electric arc, and metal wire as feedstock. The metal wire from the feedstock, melted by arc discharge, is deposited layer by layer. Another material can be added on to the top of deposited layer by replacing the feed wire from the stock, to fabricate a bimetallic structure. The purpose of this study is to collect the salient datum from the joining of two dissimilar metals. A combination of stainless steel and mild steel are considered. Proper deposition parameters, welding current along with voltage, bead width efficiency for both the metals were acquired. As a result, the physical properties of the dissimilar joint were approximate to the bulk material.

Keywords:- Additive Manufacturing; Wire And Arc Additive Manufacturing; Gas Metal Arc Welding; Stainless Steel; Mild Steel.

\section{INTRODUCTION}

Dissimilar metal joining, as the name suggests, is the com- bination of two or more metals possessing different physical, chemical and mechanical properties, such as wear resistance, tensile strength, electrical or thermal conductivity, corrosion resistance etc. The major objective is to omit the disadvantages of both along with optimizing the integral performance [1]. The conventional processes for joining of dissimilar metals include casting, explosive welding, rolling, extrusion, diffusion bonding, powder metallurgy, etc.

But some of these processes are not efficient as:

- difficulty in the fabrication of intricate shapes

- Not cost effective

while some of the other processes are being used.

The main advantage of dissimilar metal joining can be assessed with an assist. Copper alloy is acquitted with good properties while the con being its high price. So when a copper alloy is composed with steel, reduces the cost, which implies composed material is effective for many applications, including space industry [1].

Difference between conventional methods and additive man- ufacturing is by the process itself; layer by layer deposition. Additive manufacturing has become one of the most developing areas from the past thirty years [1]. Power bed fusion, directed energy deposition are two of the popular AM methods. When geometrical complexity and accuracy is in account, then the preferable methods are selective laser melting (SLM) and electron beam melting (EBM), often referred as first category, but due to low efficiency and high cost these are restricted to the production of high value and low production parts. WAAM, placed in the second category, is the preferred choice when cost and efficiency is considered. Fully fledged welding technique, GMAW, and the usage of easily accessible wire material boosts its efficiency and cuts cost. This makes it combative against other AM techniques, even though, it struggles in geometrical complexity [1].

WAAM is the technique applied. It is derived from welding, although there are differences when dissipation of heat is the factor. The heat transfer, for welding, from the molten pool to the substrate is direct while the heat conductance, in the 
case of WAAM, is partial as the transfer of heat from layer by layer to substrate causes the decrease in the heat input to the substrate along with dissipation of heat in air due to convection and radiation [1]. When the layer increases, thermal resistance towards the substrate also increases, hence lagging the solidification process [2]. Weld-bead parameter is another important aspect of WAAM. The loss of efficiency in the geometrical complexity is a result of variations in bead parameters. With over heat dissipation difference in the bead geometry can be observed [1].

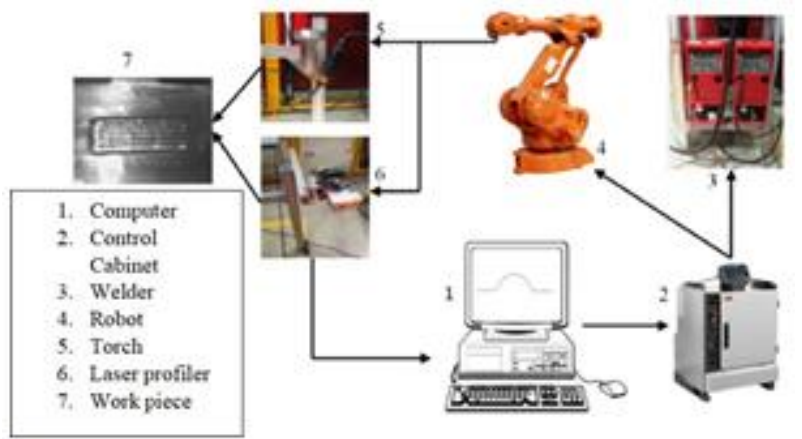

Fig. 1:- Diagram of WAAM robotic setup assisted by laser power source [5]

WAAM hardware consists of: (i) welding power source, (ii) welding torch, (iii) metal wire feeding system. Mostly (ii) and (iii) are connected to a robotic system or via a simulation software which runs on computer [3]. Gas Metal Arc Welding, abbreviated as GMAW, is the preferred process: the metal feed wire is the consumable electrode, and for the smoothness of the weld, the weld torch is placed coaxial to the consumable electrode. The movement of the weld torch is determined by the computer numerical control gantries (robotic system) [4]. Owing to its wide range of mechanical and physical properties, stainless steel is one of the highly recommended materials used for structural applications in nuclear industries, power plants, heavy load engineering applications, high temperature vessels, construction purposes and various other industrial uses. Considering its high end mechanical properties it can be directly applied into constructions, but the cost of the building the structure will increase due to the high material cost of stainless steel. The prominent agenda of selecting an efficient material for constructional purposes lay on certain factors such as low material cost, low fabrication cost, weldability of the material, the strength of the weld joints it can form and easy fabrication process. Considering all these factors, stainless steel can be effectively applied into structural construction purposes with the help of mild steel via dissimilar joining, that too quite efficiently [5].

SS308L and MS are the experimented metal feeding wire used here. The chemical composition of SS308L is specified in Table 1.
The stainless steel provides good corrosion resistance, here the Ni provides corrosion resistance while making the stainless steel ductile. Whereas MS comprises of:

\begin{tabular}{|c|c|c|c|c|c|c|c|c|}
\hline Network & $\mathrm{Fe}$ & $\mathrm{Cr}$ & $\mathrm{Ni}$ & $\mathrm{Mn}$ & $\mathrm{Si}$ & $\mathrm{C}$ & $\mathrm{P}$ & $\mathrm{S}$ \\
\hline content & 63.5 & 19.5 & 9 to & 1 to & 0.3 to & 0.03 & 0.03 & 0.03 \\
$\%$ & to 68 & to 21 & 11 & 2.5 & 0.65 & & & \\
\hline
\end{tabular}

Table 1:- The Chemical Composition Of SS308L [6]

\begin{tabular}{|c|c|c|c|c|c|c|c|c|}
\hline Network & $\mathrm{Fe}$ & $\mathrm{Cr}$ & $\mathrm{Ni}$ & $\mathrm{Mn}$ & $\mathrm{Si}$ & $\mathrm{C}$ & $\mathrm{P}$ & $\mathrm{S}$ \\
\hline $\begin{array}{c}\text { content } \\
\%\end{array}$ & 98.4 & 0.8 & 0.40 & 0.18 & 0.069 & 0.040 & 0.040 & 0.01 \\
\hline
\end{tabular}

Table 2:- The Chemical Composition Of Mild Steel [7]

MS, when comparing to SS, is less brittle which implies better strength for SS.MS exhibits ferromagnetism; magnetic material. When these two metals are joined, expecting the interface to have proper metallurgical bonding. The combination is supposed to achieve the best attributes of both the metals. Major objectives of this study is to analyze and acquire the appropriate values of different parameters for the MS - SS joint, i.e., to obtain the stable values for voltage, weld current, weld speed, bead geometry, etc.

\section{REVIEW ON MANUFACTURING OF A BIMETALLIC STRUCTURE OF SS308L AND MILD STEEL THROUGH WIRE ARC ADDITIVE MANUFACTURING}

Fang $\mathrm{Li}$ et al. [1] focused on bringing a new thermoelectric cooling system into the WAAM process so that it can reduce the difference in the elimination of the heat that is existing between the layers of deposited metal. The results obtained through effective utilization of the cooling system in WAAM process showed that there was in increase in the exploitation of the material by $16.3 \%$ and the error in the bead width was also reduced by $56.8 \%$. A total increase in the product fabrication time was also observed by $60.9 \%$ as the dwell time between the depositions of successive layers was reduced eventually by the incorporation of the cooling system.

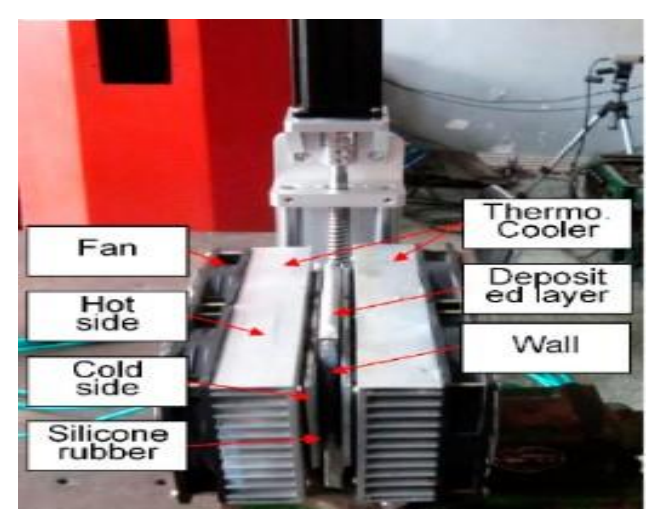

Fig. 2:- Thermoelectric cooling system incorporated with WAAM setup [1] 
Yunpeng Nie et al. [2] discussed about the fabrication of 4043 Al-alloy components by cold metal transfer through WAAM technique. One of the major outputs that could be collected from the results was that the prototyping of the alloy sections through WAAM + cold metal transfer could ensure that the arc starting current was increased as well as the arc ending current was decreased - which can avoid the downfall of melt or formation of molten lumps. Large columnar grains and dendrites were visible in the microstructure of the fabricated parts and majority of the microstructure is contained with aluminous eutectic phases as well as aluminium. Among the interfaces of the aluminium and eutectic phase, silicon is segregated. Also the mechanical properties of the fabricated alloy parts were also quite good.

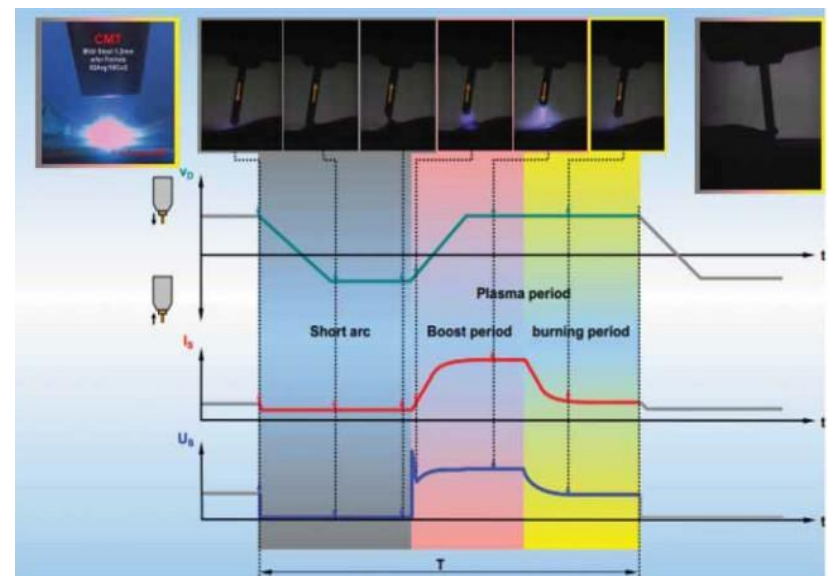

Fig. 3:- Cold Metal Transfer - Welding Diagram [2]

Liming Liu et al. [3] discussed about the manufacturing of a mild steel-silicon bronze bimetal through gas metal arc weld based shaped metal deposition which is a prominent additive manufacturing technique. Materials used were Q235B steel as the substrate, ER70S-6 mild steel wires of diameter $1.2 \mathrm{~mm}$ and $\mathrm{SG}-\mathrm{CuSi} 3$ silicon bronze wires of diameter $0.8 \mathrm{~mm}$. Through optimization they concluded that to get a $130 \mathrm{~mm}$ long and $8 \mathrm{~mm}$ wide silicon bronze bead on the MS, the weld current shall be $180 \mathrm{~A}$ as well as a weld speed of $600 \mathrm{~mm} / \mathrm{min}$. The interface zone of the structure showed the presence of mixing of -Fe and $-\mathrm{Cu}$. At the interface itself, the bronze side was found to have contained with $\mathrm{Fe}$ elements concentrated with the $\mathrm{Si}$ from silicon bronze. The joint performed a good tensile strength of $305 \mathrm{MPa}$.

S. W. Williams et al. [4] shared a study and research material on a particularly wide topic, i.e., wire and arc additive manufacturing. Wire arc additive manufacturing is a manufacturing method in which the heat source is supplied by the a manufacturing is a manufacturing method in which the heat source is supplied by the arc whereas the feedstock material is supplied in the form of wire. A regular WAAM hardware setup would be consisted of a power source, wire feeder and welding torch. The motion of the welding torch is controlled by a computer aided robot, so that any metal deposition can be done through automated procedures. Can be effectively used for manufacturing products both in small scale as well as large scale. Prominent advantages extended by

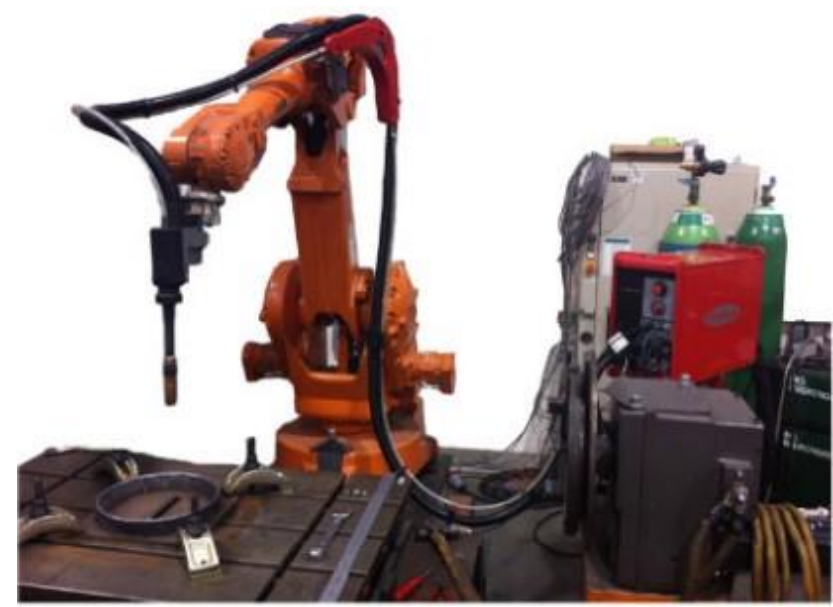

Fig. 4:- A standard automatic-WAAM setup [4]

WAAM technique include increased deposition rates compared to other traditional manufacturing processes, high yield as it minimize the material wastage and comparatively lower feedstock cost.

Donghong Ding et al. [5] discussed on laying overlapping multiple beads using wire arc additive manufacturing technique with the aid of a robot. Rather than the traditional flat top overlapping model of multiple bead, they followed a tangent overlapping model. Following the traditional FOM, it became clear that this model is giving only a little consideration for the concept of optimum centre distance and critical valley concept. Thus the chances of getting uneven deposits of metal having different heights are a lot higher. The new model proposed (TOM) by Donghong Ding et al. provides accurate vision over the critical centre distance as well as the critical valley concept, and can produce a very stable and sound deposits.

Van Thao Le et al. [6] used gas metal arc based wire arc additive manufacturing method to manufacture thin-walled parts of 308L stainless steel. It was successfully completed and the metallurgical as well as the mechanical aspects of the product were observed. From the microstructure, they found out that the middle and bottom regions of the wall were characterized with the presence of columnar dendrites. Equiaxed dendrites were observed at the top of the wall as well as the HAZ region between two distinct layers. Apart from the wall regions, the microstructure of the product showed the presence of $\gamma$ austenite dendrites which contained little amount of $\delta$ ferrite phases.

Radha Raman Mishra et al. [7] focused on a comparative study based on both TIG and MIG welding of dissimilar metal joining of stainless steel and mild steel. Comparing both the techniques after finishing the welding, it was proven that TIG is more efficient than MIG welding - which comes out as the 
result as low porosity occurred in the dissimilar joining as well as the low amount of precipitation of carbon. Radha Raman Mishra et al. observed that trying the same weld in MIG led to development of cracks at the time of welding and also the amount carbon precipitation at the joints is so high that it reduces the ability of resistance to corrosion of the joint. Also found that the in both MIG and TIG welding techniques, dissimilar joint between MS and SS304 has a very low ultimate tensile stress.

Bintao Wu et al. [8] discussed the emerging trend in using the wire arc additive manufacturing techniques. Upon the source of heat provided WAAM is classified into three: Gas Tungsten Arc Weld based, Gas Metal Arc Weld based and Plasma Arc Weld based. WAAM through GMAW offers less stability, more fumes, high deposition rate and increased spatter. Major defects that are seen in WAAM-manufactured products are deformation due to residual stresses, cracking, porosity and delamination. Certain techniques are used to improve the quality of the WAAM products such as heat treatment, peening, interpass cold rolling, interpass cooling and ultrasonic impact.

\begin{tabular}{|c|c|c|c|c|c|}
\hline Network & $\begin{array}{c}\text { Ti } \\
\text { based }\end{array}$ & $\begin{array}{c}\text { Al } \\
\text { based }\end{array}$ & $\begin{array}{c}\text { Steel } \\
\text { based }\end{array}$ & $\begin{array}{c}\text { Ni } \\
\text { based }\end{array}$ & Bimetal \\
\hline Aerospace & $\checkmark$ & $\checkmark$ & & $\checkmark$ & $\checkmark$ \\
\hline Automotive & & $\checkmark$ & $\checkmark$ & & $\checkmark$ \\
\hline Marine & $\checkmark$ & & $\checkmark$ & & \\
\hline $\begin{array}{c}\text { Corrosion } \\
\text { resistance }\end{array}$ & $\checkmark$ & & & $\checkmark$ & $\checkmark$ \\
\hline $\begin{array}{c}\text { High } \\
\text { temperature }\end{array}$ & $\checkmark$ & & & $\checkmark$ & $\checkmark$ \\
\hline $\begin{array}{c}\text { Tools and } \\
\text { molds }\end{array}$ & & & $\checkmark$ & & \\
\hline
\end{tabular}

Table 3:- Materials Used For Fabrication Of Parts For Specific Applications Using Waam [8]

Takeyuki Abe et al. [9] experimented with layer by layer de- position of stainless steel and nickel-based alloy using WAAM technique. Welding is done using GMAW-based WAAM, where the movement of the welding torch is controlled by a computer-aided controller. The materials used are YS308L which is equivalent to SUS304L and Ni6082 which is equiva- lent to Inconel 600. After metallurgical observation it was clear that no weld defects were found in the near border of interface joint and the mild steel sections respectively. The welded joint fractured around the mild steel part rather than the stainless steel part because of the much lower strength offered by mild steel relatively. After conducting the bending tests, it was found that the dissimilar weld joint offers the best bending strength $4857 \mathrm{MPa}$ which comes out of its property of high resistance to bending.

Leilei Wang et al. [11] discussed about variations in properties of $316 \mathrm{~L}$ stainless steel manufactured through WAAM. Two types of arc modes were used in the manufacturing of the product - SpeedPulse and SpeedArc - which were practically confirmed as stable, offer excellent structural quality and efficient enough. Bothe the arc modes provide almost the same rate of deposition. SpeedArc process extends a higher cooling rate and also offers a lower heat input. Thus, both at the bottom and upper layers, SpeedArc mode can bring fine grained structures. Due to this fine grained structure produced by SpeedArc mode, the hardness as well as the tensile strength values of the products manufactured through SpeedArc method will be higher than that of the component produced through SpeedPulse mode.

D. Ananthpadmanabhan et al. [12] discussed about mechan- ical properties of the friction weld joint between stainless steel and mild steel. Selected specimens had a length of $75 \mathrm{~mm}$ as well as diameter of $15 \mathrm{~mm}$ and also were in cylindrical shapes. The experiment was successful and inferred that friction welding can be effectively employed for joining of dissimilar steels. The joint obtained has structurally strong enough but could only ensure an average ductility. The comparatively lower ductility is explained with the presence of phosphorus as well as sulphur contents in the steel. The differences in hardness values of the base SS, base MS and the weld joint is explained with the help of diffusion and recrystallization taking place.

R.A. Rahman Rashid et al. [13] discussed about the metal-lurgical properties of $316 \mathrm{~L}$ stainless steel cladding on a mild steel substrate. Along the track laid, a decrease in the dilution content was found towards the end of the track. The clad region dilution can be represented in mathematical terms as:

$D \approx d_{p} /\left(d_{p}+t_{c}\right)$ 
At the interface, in weld metal area of YS308L it was found that $\delta$-ferrite had an increased grain size than usual which occurred due to the heat effect as Ni6082 was deposited and in weld metal area of Ni6082 presence of austenite grain was found. The joint was also found to be strongly bonded so that it can be used for mechanical components. Offers corrosion and high temperature resistance.

I.O. Oladele et al. [10] discussed about microstructural and mechanical properties of dissimilar metal welded joint of SS304L and mild steel plates of 5mm thickness. Process is carried out using GTAW. After welding, the tensile tests were carried out and it was found out that the stainless steel part offers the highest tensile strength with $805.3 \mathrm{MPa}$ followed by 486.2 MPa and 286.3 MPa offered by the dissimilar metal weld where $\mathrm{D}$ is the average dilution, $\mathrm{d} p$ is the depth of pen- etration of clad metal and $t c$ is the thickness of the clad. The microstructure of the clad region contained equiaxed austenitic grains with a large ratio of columnar grains found around the interface between the clad metal and the substrate.

HAZ showed the presence of lath martensite coexisting with Widmanstätten ferrite along the sides of interface of clad and substrate.

Md. Rumman Ul Ahsan et al. [14] discussed on the fabrication of a bimetallic structure made of $316 \mathrm{~L}$ austenitic stainless steel and low carbon steel using wire arc additive manufacturing technique. Fabrication used GMAW-based WAAM technique in such a way that both low carbon steel and SS 316L can be laid successively. The experiment was successful and they found out that at the interface, there were two distinct regions with SS as well as LCS deposits. Also by inferring to the hardness profile, due to the incoming attribute of chromium from SS, there was a sudden increase in the hardness at the interface. In the tensile test, the structure failed at the LCS side due to the lower tensile strength of low carbon steel.

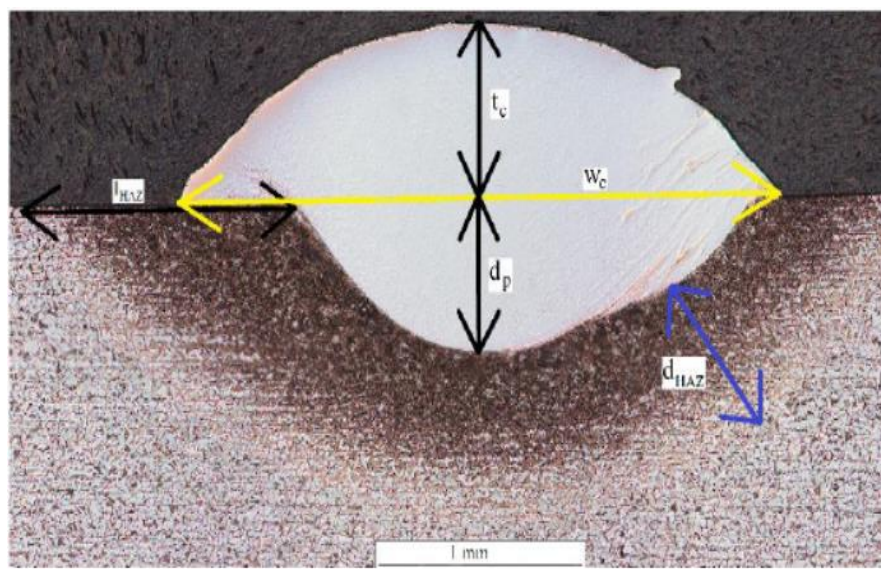

Fig. 5:- Transverse view of the clad deposition and the parameters [13]
Xiaohui Chen et al. [15] discussed about the mechanical as well as microstructural aspects of an additively manufactured structure of austenitic stainless steel 316L. The WAAM technique followed here is GMAW-based and the torch was controlled with help of a KUKA robot which had 6-axis motion. The parameters regarding the manufacturing of the structure were given as: $300 \mathrm{~A}$ of current, $28 \mathrm{~V}$ of voltage and $10 \mathrm{~m} / \mathrm{min}$ of feed rate of the stainless steel wire spool. In the manufactured plate, the middle region had bigger columnar grains due to vertical alignment of the austenitic dendrites and the around the edges smaller columnar grains were found due to the bend experienced by some dendrites towards the plate surface. Found that the tensile properties regarding the additively manufactured 316L plate at ambient temperatures are just similar to that the wrought $316 \mathrm{~L}$ and can be effectively chosen over wrought $316 \mathrm{~L}$ for industrial applications.

Md. R. U. Ahsan et al. [16] discussed about the effects of heat treating on bimetallic structure of low carbon steel and SS316L which is additively manufactured. Applying the correct heat treatment parameters to the structure, the yield strength, ultimate tensile strength and the elongation, can all be improved very effectively. Mechanical properties of the structure is improved by the formation of ferrite-bainite structure which occurred as the transformation of ferrite in the deposited LCS took place. Heat treating at $800^{\circ} \mathrm{C}$ for 1 hour proved that the amount of ferrite in the BAMS structure increased and thus it led to its low ductility. Heat treating the sample above $950^{\circ} \mathrm{C}$ did not bring about any changes that are valid. Whereas the optimum heat treating condition for the BAMS structure was inferred as $950^{\circ} \mathrm{C}$ for 1 hour as it gave slight improvement in the mechanical properties.

Andrés L García Fuentes et al. [17] discussed on a study of effects of cyclic loads on the butt-welded joints of structural steel ASTM A537 and stainless steel 304L. The filler material used for the welding is $\mathrm{SS} 308 \mathrm{~L}$ and the procedure is done using the GMAW technique. In order to check the mechanical strength of the welded specimen, certain mechanical tests like Charpy impact test, microhardness profile through Vickers and bending test were all done on pre-cracked specimens in order to know the extend and rate of growth of crack. The tests showed that despite the high microhardness values around HAZ and the fusion line between SS304L and welding, through which the crack propagated faster in the pre-crack test, the joint performed with an optimum mechanical beaviour.

Bintao Wu et al. [18] discussed about the improvement in the strength of the interface between bimetallic joint of ER70S-6 steel and ERNi-1 nickel, when accommodating interweaving deposition method. WAAM technique used here is GTAW based. In order to get a stable melt pool, the angle between the substrate and the weld wire feeder was fixed at $60^{\circ}$ and the shielding gas used in here is pure argon of almost $99.9 \%$ purity. Total of 15 layers were laid with each layer having an approximate height of $10 \mathrm{~mm}$. After producing a successful component, it was evident that the interface at the joint was 
offering more tensile strength than steel or nickel. The primary reason for this highly improved mechanical strength is the interweaving method that was followed for the deposition as it eliminated the chance of weak fusion boundaries at the joint.

Shamsul Baharin Jamaludin et al. [19] focused on the mechanical improvements and properties that can be drawn from the dissimilar welding of mild steel and stainless steel. The joining of mild steel plates with austenitic stainless steel 304 is done by gas tungsten arc welding and for electrodes there were mainly two distinct ones of mild steel and stainless steel. They optimized the process with an arc current of 100A. After comparing both the welded samples, Shamsul Baharin Jamaludin et al. inferred that the sample joined with stainless steel electrode showed better tensile and yield strength than that of the sample joined by mild steel electrode. About the failure, welded samples underwent failure around the mild steel end as it is the least favourable region considering the strength among base stainless steel, the fusion and the heat affected regions.

\section{CONCLUSION}

The conclusions deduced in this review are:

A dissimilar joint between MS and SS can be practically viable with WAAM. It can be toiled through GMAW technique.

$>$ Throughout the fabrication, the molten metal experienced a heat extraction, which was directional, followed by remelting and quick solidification.

$>$ To avoid the problematic situation of humping and collapsing, increase the arc initial current and decrease the arc final current.

$>$ Effective deposition and its process parameters were optimized i.e. the exact values of the weld current, voltage, feed wire supply, etc. was noted. When there is variation in any of the process parameters, which affects the effective deposition of the material.

$>$ Further, the mechanical properties of the joint were comparable with the initial materials (i.e. SS and MS).

$>$ Fine grained microstructures can be acquired with increasing cooling rate. Thermoelectric cooling can be used to increase the cooling rate. It can improve the bead width error as well reduce the dwell time for dissipation of heat among the deposited layers. Even the productivity rate can be improved with thermoelectric cooling.

$>$ Adjusting the angle between the feed wire and the sub-

$>$ strate to $60^{\circ}$, can attribute towards a very stable weld pool and uniformity in the bead width.

In conclusion, WAAM proves to be a sensible method for the fabrication of dissimilar metal joining. Significant improvements on the fabrication, through WAAM, of complex shapes are attainable in the near future.

\section{REFERENCES}

[1]. F. Li, S. Chen, J. Shi, Y. Zhao and H. Tian, "Thermoelectric Cooling- Aided Bead Geometry Regulation in Wire and Arc-Based Additive Manufacturing of Thin-Walled Structures," Applied Sciences, vol. 8, no. 2, p. 207, 2018.

[2]. Y. Nie, P. Zhang, X. Wu, G. Li and H. Y. . Z. Yu, "Rapid prototyping of $4043 \mathrm{Al}$-alloy parts by cold metal transfer," Science and Technology of Welding and Joining, vol. 23, no. 6, pp. 527-535, 2018.

[3]. L. Liu, Z. Zhuang, F. Liu and M. Zhu, "Additive manufacturing of steel-bronze bimetal by shaped metal deposition: interface character- istics and tensile properties," The International Journal of Advanced Manufacturing Technology, vol. 69, p. 2131-2137, 2013.

[4]. S. W. Williams, F. Martina, A. C. Addison, J. Ding and G. P. . P. Colegrove, "Wire + Arc Additive Manufacturing," Materials Science and Technology, vol. 32, no. 7, pp. 641647, 2016.

[5]. D. Ding, Z. Pan, D. Cuiuri and H. Li, "A multi-bead overlapping model for robotic wire and arc additive manufacturing (WAAM)," RoboticsandComputerIntegratedManufacturing, vol. 31, pp. 101-110, 2015.

[6]. V. T. Le and D. S. Mai, "Microstructural and mechanical characteristics of 308L stainless steel manufactured by gas metal arc welding-based additive manufacturing," Materials Letters, vol. 271, 2020.

[7]. R. R. Mishra, V. K. Tiwari and a. R. S, ”A Study of tensile strength of MIG and TIG welded diddimilar joints of mild steel and stainless steel," International Journal of Advances in Materials Science and Engineering, vol. 3, pp. 23-32, 2014.

[8]. B. Wu, Z. Pan, D. Ding, H. L. Dominic Cuiuria, J. Xu and J. Norrish, "A review of the wire arc additive manufacturing of metals: properties, defects and quality improvement," Journal of Manufacturing Processes, vol. 35, pp. 127-139, 2018.

[9]. T. Abe and H. Sasahara, "Dissimilar metal deposition with a stainless steel and nickel-based alloy using wire and arcbased additive manufac- turing," Precision Engineering, vol. 45, pp. 387-395, 2016.

[10]. I. Oladele, O. Betiku, A. Okoro and O. Eghonghon, "Microstructure and Mechanical Properties of 304L and Mild Steel Plates Dissimilar Metal Weld Joint," ACTA TECHNICA CORVINIENSIS - Bulletin of Engineering, vol. 11, no. 2, pp. 77-81, 2018.

[11]. L. Wang, J. Xue and Q. Wang, "Correlation between arc mode, microstructure, and mechanical properties during wire arc additive manufacturing of 316L stainless steel," Materials Science Engineering A, vol. 751, p. 183-190, 2019.

[12]. D. Ananthapadmanaban, V. S. Rao, N. Abraham and K. P. Rao, "A study of mechanical properties of friction welded mild steel to stainless steel joints," Materials and Design, vol. 30, p. 2642-2646, 2009. 
[13]. R. R. Rashid, S. Abaspour, S. Palanisamy, N. Matthews and M. Dargusch, "Metallurgical and geometrical characterisation of the 316L stainless steel clad deposited on a mild steel substrate," Surface Coatings Technology, vol. 327, pp. 174-184, 2017.

[14]. M. Ahsan, A. Tanvir, T. Ross, A. Elsawy and M.-S. a. K. D. Oh, "Fabrication of bimetallic additively manufactured structure (BAMS) of low carbon steel and $316 \mathrm{~L}$ austenitic stainless steel with wire + arc additive manufacturing," Rapid Prototyping Journal, vol. 26, no. 3, pp. 519-530, 2019.

[15]. X. Chen, J. Li, Z. Huang, H. Wang, X. Cheng and B. He, "Microstruc- ture and mechanical properties of the austenitic stainless steel $316 \mathrm{~L}$ fabricated by gas metal arc additive manufacturing," Materials Science Engineering A, vol. 703, pp. 567-577, 2017.

[16]. M. R. U. Ahsan, A. N. M. Tanvir, G.-J. Seo, B. Bates, W. Hawkins, C. Lee, P. K. Liaw, M. Noakes and A. N. a. D. B. Kim, "Heat-treatment effects on a bimetallic additively-manufactured structure (BAMS) of the lowcarbon steel and austenitic-stainless steel," Additive Manufacturing, vol. 32, 2020.

[17]. A. L. G. Fuentes, R. Salas, L. Centeno and a. A. V. d. Rosario, "Crack growth study of dissimilar steels (Stainless - Structural) butt-welded unions under cyclic loads," Procedia Engineering, vol. 10, p. 1917-1923, 2011.

[18]. B. Wu, Z. Pan, Z. Qiu, K. Carpenter, T. Wang, D. Ding, S. vanDuin and

[19]. H. Li, "Enhanced interface strength in steel-nickel bimetallic component fabricated using wire arc additive manufacturing with interweaving deposition strategy," Journal of Materials Science Technology, vol. 52, pp. 226-234, 2020.

[20]. S. B. Jamaludin, M. M. Noor, S. K. A. Kadir and K. R. Ahmad, "Mechanical Properties of Dissimilar Welds Between Stainless Steel and Mild Steel," Advanced Materials Research, vol. 795, pp. 74-77, 2013. 